
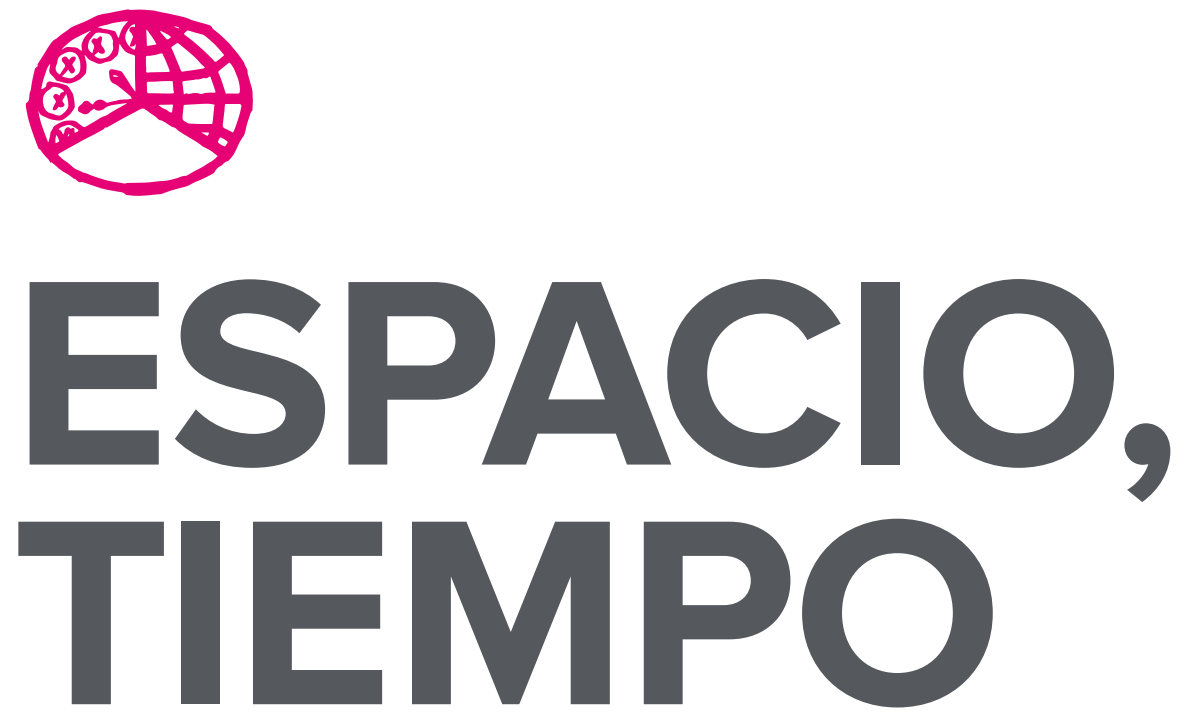

AÑO 2016

ISSN 1131-7698

E-ISSN 2340-1354
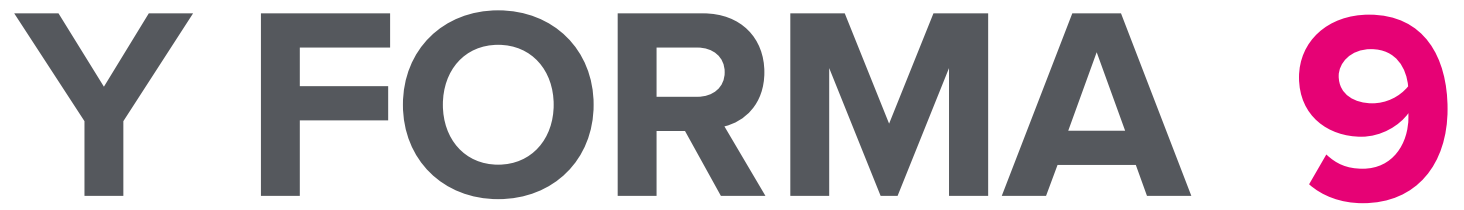

SERIE I PREHISTORIA Y ARQUEOLOGÍA

REVISTA DE LA FACULTAD DE GEOGRAFÍA E HISTORIA 


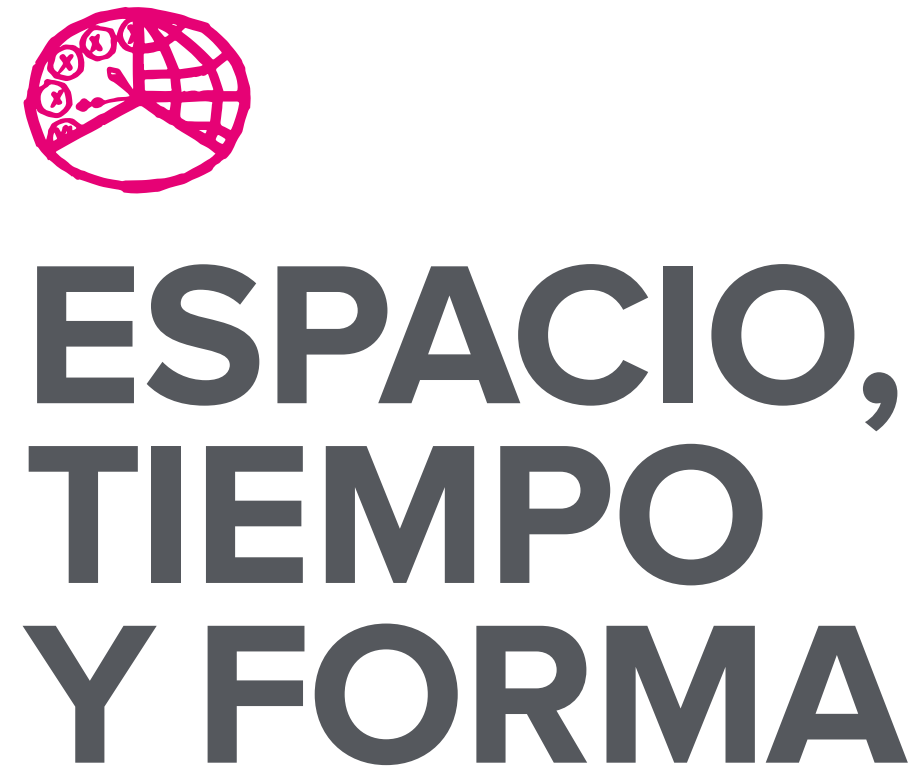

AÑO 2016

ISSN 1131-7698

E-ISSN 2340-1354

SERIE I PREHISTORIA Y ARQUEOLOGÍA

REVISTA DE LA FACULTAD DE GEOGRAFİA E HISTORIA

DOI: http://dx.doi.org/10.5944/etfi.9.2016

\section{UกED}

UNIVERSIDAD NACIONAL DE EDUCACIÓN A DISTANCIA 
La revista Espacio, Tiempo y Forma (siglas recomendadas: ETF), de la Facultad de Geografía e Historia de la UNED, que inició su publicación el año 1988, está organizada de la siguiente forma:

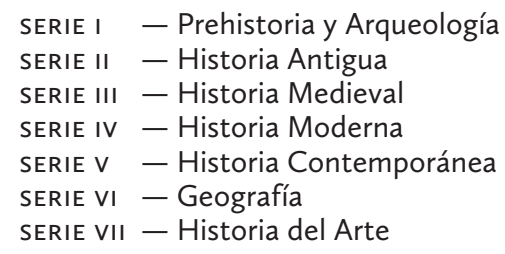

Excepcionalmente, algunos volúmenes del año 1988 atienden a la siguiente numeración:

$$
\begin{aligned}
& \mathrm{N}^{\circ}{ }_{1} \text { - Historia Contemporánea } \\
& \mathrm{N}^{\circ} 2 \text { - Historia del Arte } \\
& \text { N. }{ }^{\circ} 3 \text { - Geografía } \\
& \text { N. }{ }^{\circ} 4 \text { - Historia Moderna }
\end{aligned}
$$

ETF no se solidariza necesariamente con las opiniones expresadas por los autores.

Espacio, Tiempo y Forma, Serie I está registrada e indexada, entre otros, por los siguientes Repertorios Bibliográficos y Bases de Datos: LATINDEX, DICE, ISOC (CINDOC), RESH, IN-RECH, DIALNET, E-SPACIO UNED, CIRC 2.0, MIAR 2OI6, CARHUS 2OI4, FUENTE ACADEMICA PREMIER, PERIODICALS INDEX ONLINE, ANTROPOLOGICAL LITERATURE, FRANCIS, ULRICH'S, SUDOC, ZDB, L'ANNÉE PHILOLOGIQUE, DULCINEA (VERDE).

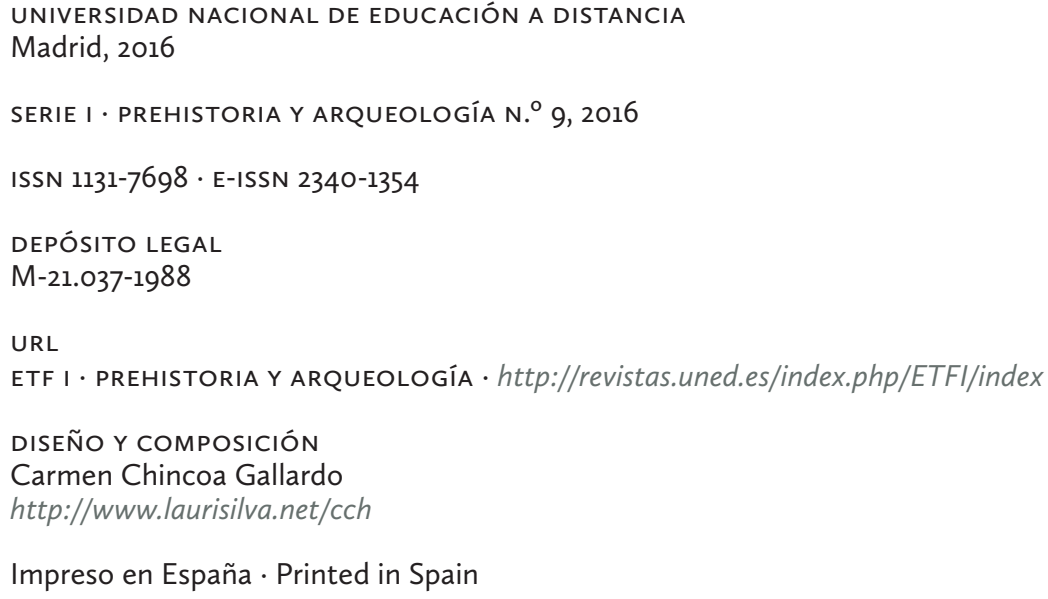




\title{
LA PLACA DE AMIADOSO (ALLARIZ, OURENSE): NUEVOS DATOS SOBRE EL USO DEL MÁRMOL LOCAL EN EL NOROESTE DE HISPANIA A PARTIR DE UN ESTUDIO INTERDISCIPLINAR
}

\section{THE AMIADOSO PLAQUE (ALLARIZ, OURENSE): NEW DATA FROM AN INTERDISCIPLINARY STUDY ON THE USE OF LOCAL MARBLE IN THE NW OF HISPANIA}

\author{
Silvia González Soutelo² \& Sergio Vidal Álvarez² \& Anna Gutiérrez Garcia-M. \& \\ Hernando Royo Plumed ${ }^{4}$ \\ Recibido: 10/11/2016 - Aceptado: 28/11/2016 \\ DOI: http://dx.doi.org/10.5944/etfi.9.2016.17540
}

\section{Resumen}

En este artículo se presenta un nuevo estudio sobre la placa de Amiadoso (Allariz, Ourense), que consiste en un análisis interdisciplinar en el que se combina la perspectiva estilística con el estudio arqueométrico del soporte material. De esta manera, a la contextualización cronológica de las diferentes fases de la pieza a partir de su estudio formal, hemos unido la identificación del mármol utilizado, cuyo resultado confirma un origen local (área de O Incio). Este nuevo dato aporta información esencial, dada la excepcionalidad de la pieza, para conocer aspectos vinculados a la calidad técnica de los talleres locales, y consecuentemente sobre las implicaciones económicas, sociales y políticas de este tipo de producciones dentro del noroeste de la Península Ibérica.

\section{Palabras clave}

Gallaecia; objetos romanos reutilizados; mármol; arqueometría; talleres locales.

\section{Abstract}

In this paper we present a new study on the Amiadoso plaque (Allariz, Ourense), in which this Roman object has been analysed from an interdisciplinary point of view based in the combination of stylistic and archaeometric studies. Consequently,

\footnotetext{
1. GEAAT, Universidade de Vigo. Correo electrónico: silviagonzalez@uvigo.es

. Museo Arqueológico Nacional/UNED. Correo electrónico: sergio.vidal@mecd.es

3. IRAMAT-CRP2A (UMR 506o CNRS-UBM)/ LaScArBX.

Correo electrónico: anna.gutierrez@u-bordeaux-montaigne.fr

4. ICAC, Institut Catalá d’Arqueologia Clàssica. Correo electrónico: hroyo@icac.cat
} 
we have linked up the analysis of the different artistic phases of this piece from a formal study with the identification of the marble used, which confirms a local provenance (O Incio area). These new data provide essential information, given the exceptional nature of this object, to recognize aspects related to technical quality of local workshops and consequently about social, economic and political implications of this type of productions in the Northwest of the Iberian Peninsula.

\section{Keywords}

Gallaecia; Roman re-used objects; marble; archaeometry; local workshops.

\section{INTRODUCCIÓN}

Como en muchas provincias del Imperio Romano, el empleo del mármol y otras rocas ornamentales fue un aspecto fundamental en la implantación de la civilización y cultura romana en Hispania. En el contexto de la península Ibérica, los resultados del trabajo de varios equipos han confirmado la importancia del estudio de los materiales lapídeos como un aspecto indispensable para entender con todos sus matices no sólo la evolución socio-económica, ideológica e incluso cronológica de la Hispania romana, sino también la riqueza y complejidad de la industria de la piedra en determinados territorios de nuestra geografía ${ }^{5}$. Todos ellos han ido configurando un panorama cada vez más completo de los recursos líticos existentes en las Hispaniae, entre los que se encuentran mármoles de gran calidad estética y técnica, con demostrada explotación en época antigua. Sin embargo, existen aún algunas lagunas territoriales importantes, especialmente en lo que se refiere a la zona norte y noroeste peninsular.

Conscientes de esa realidad, planteamos la necesidad de abordar el estudio de los materiales marmóreos explotados y usados en época romana y tardorromana en la Galicia actual ${ }^{6}$. Para ello, un aspecto clave desde el primer momento ha sido revisar los materiales presentes en este territorio desde una perspectiva

5. Sin pretender ser exhaustivos, destacamos los trabajos realizados en las regiones costeras de la Tarraconense (especialmente las actuales Cataluña y Murcia), la Bética y la Lusitania, publicados en varias monografías o volúmenes recopilatorios (Nogales Basarrate y Beltrán Fortes 2009; Àlvarez et al. 2009a, 2009b; García-Entero 2012), así como las numerosas contribuciones en los Congresos Internacionales de la Association for the Study of Marbles and Other Stones in Antiquity (ASMOSIA) (SCHVOERER 1999; HeRMANN et al. 2002; JOCKEY 2009; MANIATIS 2009; Gutiérrez Garcia-M. et al. 2012; Pensabene y Gasparini 2015) o en los Congresos de Arqueología de la Construcción organizados por el Instituto de Arqueología-Mérida (CSIC), la Università di Siena y l'École Normale Superieure de Paris desde 2007 (CAMPOREALE et al. 2008, 2010, 2012 y 2014).

6. La línea de investigación «Marmora Galicia», creada en 2012 y coordinada por las Dras. S. González Soutelo y A. Gutiérrez Garcia-M., junto al Dr. H. Royo Plumed, surge en el marco de un proyecto de investigación I+D+i titulado «La explotación y comercio de los recursos naturales en el norte de la Hispania romana: lapis, metalla, aqua (HAR2011-25011)», dirigido por la Dra. Isabel Rodà desde el ICAC, y tiene continuación en el marco del proyecto «Marmora et lapides Hispaniae: exploitation, usages et distribution des ressources lithiques de l'Espagne romaine» del LabEx Sciences Archéologiques de Bordeaux, programa financiado por la ANR ( $n^{\circ}$ ANR-10-LABX-52), y en el proyecto de $\mathrm{I}+\mathrm{D}+\mathrm{I}$ «Officinae lapidariae tarraconenses. Canteras, talleres y producciones artísticas en piedra de la provincia Tarraconensis» (HAR2015-65319-P). 
interdisciplinar que nos permitiese, por una parte, reconocer la variedad y naturaleza de los materiales (mármoles u otras rocas ornamentales) con los que se elaboraron los objetos empleados en este territorio en época romana y tardorromana ${ }^{7}$, así como analizar factores claves como su funcionalidad, procedencia y posible adscripción cronológica.

En este marco, desde 2012 hemos catalogado más de ioo piezas elaboradas en mármol dentro de este territorio. En la mayoría de los casos, la información contextual para su interpretación es realmente escasa e incierta, ya que muchos de estos materiales fueron reutilizados (fundamentalmente en iglesias prerrománicas o románicas), lo que dificulta identificar su procedencia exacta, así como la cronología de su importación o uso en Galicia. Entre estas piezas, destacamos en este estudio la conocida como placa de Amiadoso (S. Martiño de Pazó, Allariz) no sólo por la calidad de su trabajo escultórico, sino también por las singularidades cronológicas que presenta y por el soporte material en el que fue realizado, donde consideramos que se encuentran algunas de las claves de su interpretación.

Para profundizar en el estudio de esta pieza, proponemos un estudio interdisciplinar en el que se busca aportar nueva luz en su interpretación mediante la combinación del estudio estilístico con el análisis del mármol en el que fue elaborado. Este enfoque se basa en la constatación de que, si bien el estudio artístico de la pieza puede aportar datos sobre aspectos vinculados a su función y cronología, el análisis arqueométrico del soporte marmóreo empleado puede permitir identificar el tipo de mármol y, por lo tanto, su lugar de extracción. Reconocer la procedencia de la materia prima es fundamental ya que tiene implicaciones directas sobre aspectos vinculados a las redes comerciales, a la producción de elementos artísticos y a la existencia y vitalidad de talleres escultóricos en determinados ámbitos provinciales durante época romana y tardorromana. En efecto, «no resulta lo mismo, ni tiene la misma significación, si se trata de una pieza hecha con material de procedencia local o con material importado» (Lapuente y Àlvarez 2012: 73).

La placa objeto de estudio se localizó por primera vez en I945 junto con otras piezas $^{8}$, reutilizada en la antigua capilla de S. Adrián ${ }^{9}$ en la aldea de Amiadoso (parroquia de S. Martiño de Pazó), localidad ourensana perteneciente al ayuntamiento de Allariz (Figura I). La noticia de este hallazgo fue dada a conocer por Puga Brau, su descubridor (1946), así como por B. Osaba (I946), director en aquel momento del Museo Arqueológico Provincial de Ourense, en el que se depositaron estas piezas ${ }^{\mathrm{IO}}$.

7. Conservados en diferentes instituciones y yacimientos arqueológicos.

8. Así se menciona la aparición de la placa de Amiadoso junto con «dos perpiaños graníticos con una cara esculpida en relieve en la que ofrecen, dentro de un marco, sendas cruces patadas de las que penden un alfa y un omega» (FARIÑA BUSTO 1997: 313). Posteriormente se localizarían otras piezas de similar procedencia, una de ellas descrita como capitel corintio reutilizado como pila de agua, que fue depositado igualmente en el Museo Arqueológico Provincial de Ourense (MAPO).

9. Según SÁNCHEZ PARDO (2015: 98-99), que recoge la bibliografía anterior, entre los restos conservados de esta capilla se aprecia todavía muros de fábrica prerrománica, identificada inicialmente como de cronología visigoda, y posteriormente atribuida a época «mozárabe» (ca. s. X).

10. La placa de Amiadoso forma parte de la colección del Museo Arqueológico Provincial de Ourense (MAPO), donde se conserva con el $n^{\circ}$ de inventario CE002761. Para su análisis ha sido fundamental las facilidades dadas por el director del Museo Arqueológico Provincial de Ourense, X. Rodríguez González, así como por el personal de dicha 


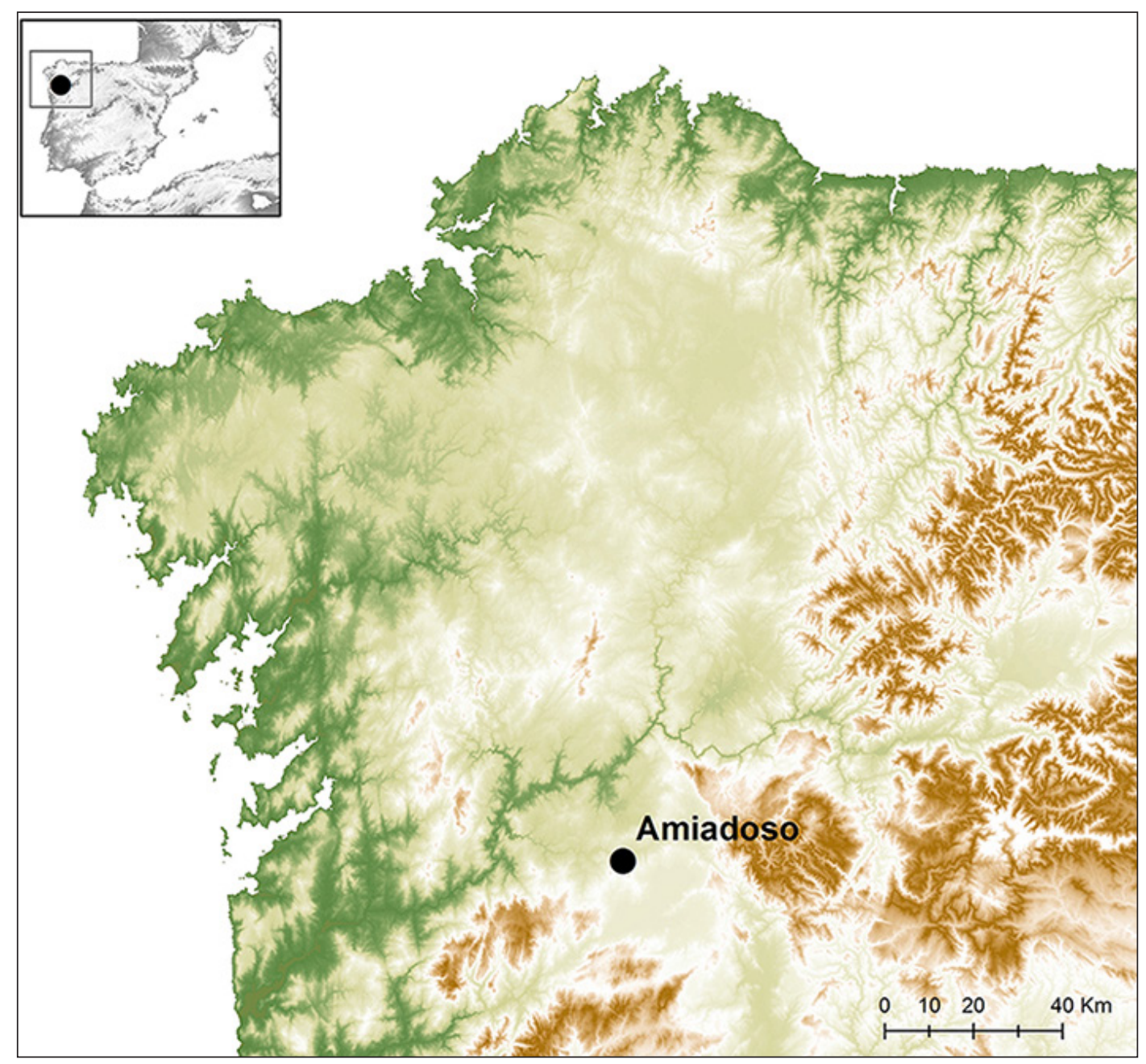

FIGURA 1. LOCALIZACIÓN DEL LUGAR DE AMIADOSO, ALLARIZ, OURENSE.

Desde entonces ${ }^{\mathrm{II}}$, dicha placa ha estado expuesta en diferentes salas del Museo, y en la actualidad, en espera de la remodelación de la sede principal de esta entidad, se puede contemplar en la sala provisional de $S$. Francisco de la capital ourensana.

En términos generales, se trata de un bloque prismático de $65 \mathrm{~cm}$. de alto, $46 \mathrm{~cm}$. de ancho y $15 \mathrm{~cm}$. de profundidad, decorado en relieve en cinco de sus seis lados en, al menos, dos momentos distintos. Está elaborado en un mármol de grano

institución, fundamentalmente en las personas de X.L. Méndez Fernández y A.M. Veiga Romero; y la Dirección Xeral do Patrimonio Cultural, Servizo de Museos e Servizo de Arqueoloxía de la Xunta de Galicia. A todos ellos, les agradecemos su ayuda e interés en este proyecto.

11. Desde ese momento la pieza ha sido estudiada y publicada en numerosas ocasiones (PugA BrAU 1946: 46; Osaba y Ruiz de Erenchun 1946; Lorenzo Fernández 1953; Palol 1967: 241; Rivas Fernández 1976; Núñez Rodríguez 1976: 185-186, nota 5; Id. 1978: 99-100; VAlle Pérez 1984: 135; Bango 1987: 36; CastiñeIras 1990; Acuña Fernández y Valle Pérez 1991; Fariña Busto 1991: 53; ArIas VILAS 1992: 123; AA.VV. 1992: nº 18; Rodríguez ColmeNERO 1993: 469-470; YZQUIERdo PerRín 1993: 150-152; FARIÑA BUSTO 1997; Id. 2004; VIDAL 2005: 6 y nota 3; VÁzQUEZ Castro 2005: 49; SÁnchez Pardo 2012a: 262; ld. 2012b: 402; Valle Pérez 2012: 332). 
fino, bien cristalizado y relativamente translúcido que presenta una alternancia de bandas netas de color blanco homogéneo y bandas de color gris claro más finas (milimétricas), más irregulares y con los límites difusos, lo que proporciona a la pieza un particular aspecto laminado. Presenta un estado de conservación irregular, habiendo sufrido una fractura en una de sus esquinas (cuya superficie de fractura, subperpendicular a la laminación, facilita el estudio de sus características), así como cierto desgaste en sus superficies decoradas, posiblemente como consecuencia de la adecuación de la pieza a su nueva ubicación en su segunda etapa de uso.

\section{ASPECTOS ESTILÍSTICOS: UN EJEMPLO DE PALIMPSESTO ESCULTÓRICO}

\section{II.1. FASE 1: PERIODO ROMANO O TARDOANTIGUO}

El costado que podemos identificar como principal y que corresponde a la fase más antigua de la pieza (Figura 2), muestra un campo rectangular moldurado que enmarca un motivo vegetal en cuya base se encuentra un conjunto de hojas de acanto con los nervios muy marcados, a partir de las que se desarrollan diversos tallos serpenteantes asimétricos que, sin llegar a conformar roleos, discurren hacia la parte superior. El relieve se trunca abruptamente en el extremo superior, pudiendo deducir que la composición se prolongaba hacia arriba, presentando continuidad de los tallos vegetales para rematarse en el extremo superior de forma indeterminada.

El conjunto de hojas de acanto de la zona inferior presenta una forma fusiforme en el centro que, creemos, corresponde al capullo que se forma en este tipo de plantas en el momento previo a su floración. No es rara la presencia de este tipo de motivo en composiciones basadas -de un modo más o menos naturalista- en la planta del acanto, alcanzando en algunos casos cronologías que llegan hasta el siglo V d.C. ${ }^{22}$. A ambos lados del motivo central la composición se completa con sendas rosáceas cuadripétalas.

Más interesante resulta la zona superior donde, a pesar del desgaste de la pieza, encontramos dos aves, la de la derecha picoteando un elemento del propio tallo vegetal y la de la izquierda, asimétrica a la anterior, cogiendo con el pico lo que parece una lombriz, motivo muy recurrente en la plástica de toda la Antigüedad, con ejemplos afines en la escultura hispánica de la Antigüedad Tardía, como un fuste de columna de Beja (Portugal) ${ }^{13} \mathrm{o}$ una placa marmórea de Orihuela (Alicante) ${ }^{14}$.

12. Así en muestras como el lateral del sarcófago de Barbatianus del Duomo de Rávena, datado a mediados del siglo V d.C. (KolLWITZ y HeRDejüRGEN 1979: 63-64 y lám. 51.4).

13. Fuste de columna de mármol datado en el siglo IV d.C., conservado en el Museu Regional de Beja (Portugal). (VIDAL 2005: 78-82, n B20, con la bibliografía anterior).

14. Pequeña placa de caliza, datada en el siglo VI d.C., conservada en el Museo Comarcal de Orihuela (Alicante). (VIDAL 2005: 109-111, n C6, con la bibliografía anterior). 


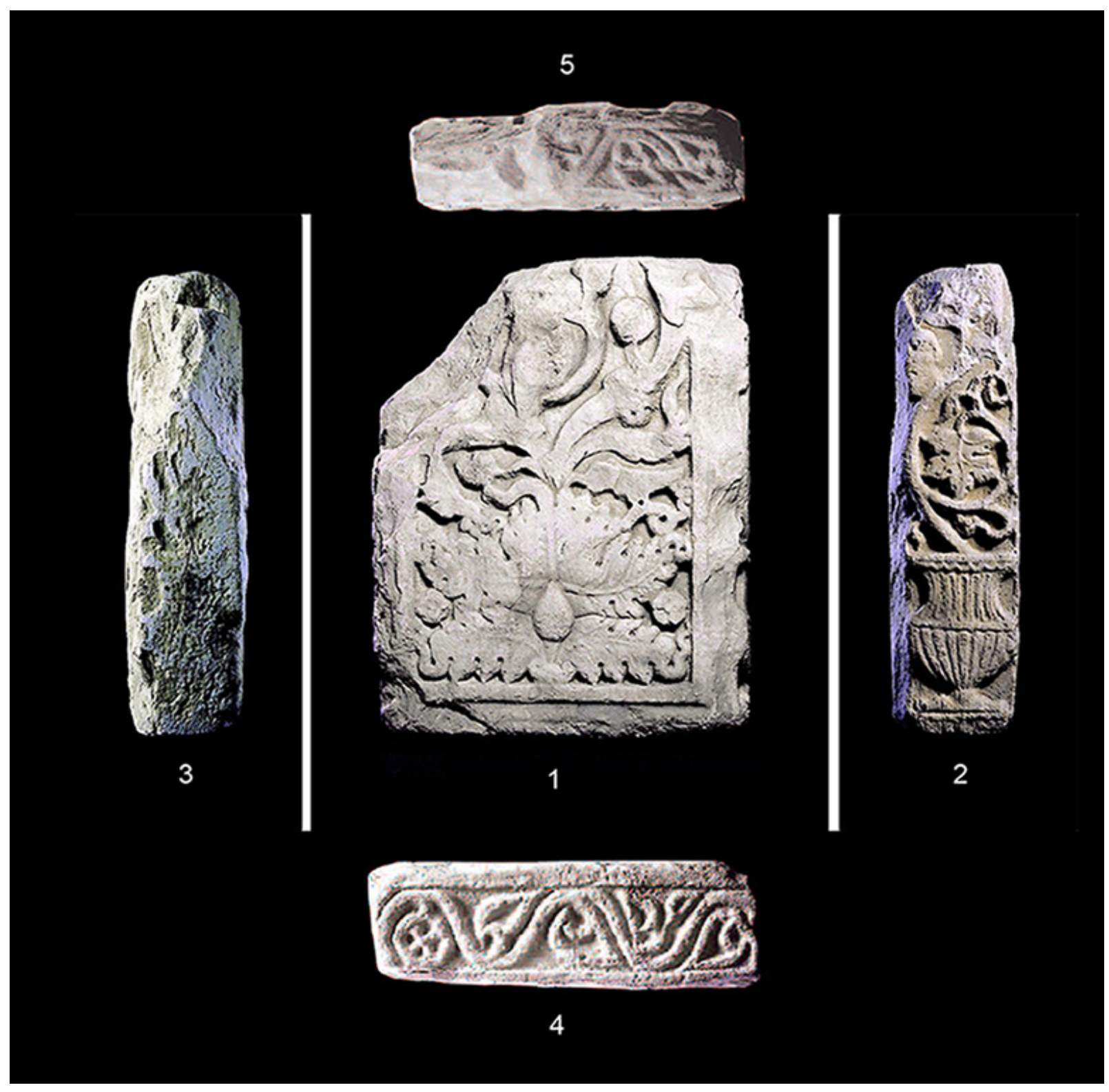

FIGURA 2. IMAGEN COMPUESTA DE LAS DIFERENTES CARAS DECORADAS EN RELIEVE DE LA PLACA DE AMIADOSO. FASE I (MONTAJE A PARTIR DE LAS FOTOGRAFÍAS DE CERES).

En el costado derecho, la pieza muestra en la base una crátera gallonada de pie cónico, boca ancha y asas prácticamente perdidas, de la que surge un roleo ascendente rematado por hojas de hiedra con los nervios muy marcados y pámpanos. Nuevamente el motivo vegetal se interrumpe en la zona superior por la rotura de la pieza, mostrando una máscara humana de perfil. La superficie del costado contrario aparece muy desgastada, fruto de un rebaje practicado ex profeso, sin embargo se advierte que en origen presentó un tipo de composición semejante a la anterior.

La iconografía de los relieves de esta primera fase de la pieza corresponde al motivo del «roleo habitado», comúnmente interpretado en clave escatológica como 
una representación del más allá paradisíaco (Toynbee y Ward Perkins I950). Llama igualmente la atención la presencia del elemento del rostro/máscara humana, que está presente en multitud de mosaicos y relieves de épocas romana y tardorromana, proporcionando entre los siglos I-VI d.C. un amplio muestrario de variantes formales e iconográficas, pudiendo aparecer tanto frontal, como de perfil $\mathrm{u}$, ocasionalmente, con los extremos del cabello y barba transformados en hojas de acanto ${ }^{15}$. Junto a los paralelos aportados por estudiosos que han dedicado su atención a este motivo como Gamer, entre los que destacan los de Lillebonne del Museo de Rouen (Gamer I970: 132, fig. 2), las columnas del Musée Carnavalet, o de Mahdia en Túnez (Gamer I97I: 489-490), se advierte la presencia de máscaras en un contexto y con una forma más similar a la presente en piezas como una de las pilastras halladas en el Canopo de Villa Adriana en Tívoli de hacia el I38 d.C. ${ }^{16}$. Por su parte, en la península Ibérica tenemos el mencionado ejemplo del fuste de Beja (Portugal), donde además de la crátera de la que salen roleos vegetales poblados por aves, hallamos hasta tres máscaras de perfil ${ }^{17}$. En todo caso, piezas como la de Amiadoso, junto con el fuste de Beja, aun partiendo formalmente de una tradición de tipo dionisíaco, transforman el contenido tradicional desviándolo hacia la materialización de un tipo de composiciones plenamente particulares, cuya realidad iconográfica queda exenta de toda vinculación de carácter religioso.

Teniendo de nuevo en cuenta la conjunción del elemento de la crátera y las aves picando racimos, temas con enorme difusión en la escultura y mosaico de época tardorromana, no es necesario buscar paralelos en geografías lejanas a Hispania (Gamer 1970: I33-I35 ${ }^{18}$ ), siendo muy reveladores ejemplos como el de los mosaicos de la Villa de Pições, datables entre los siglos III-IV d.C. (Vargas Costa I985, especialmente I03-I04 y figs. 6, I4). Este tipo de mosaicos demuestran que en Hispania, al igual que en muchos otros centros del Imperio, arraigaron este tipo de modelos iconográficos en los que el binomio del roleo y el ave juegan un papel primordial.

15. Por mencionar algunos ejemplos destacados los frisos del Templo del Sol erigido en Roma por Aureliano en el 273 (Giuliano 1985: 17-30, n I, 5, B. PetTinau, nº inv. 80100-80110); la crátera de mármol gris de hacia el 400 del Museo Nazionale Romano (SEVERIN 1970: 211-218; SAPELLI 1998: 61, nº 30); o el grupo de capiteles y cimacios del s. VI d.C. del Museo Arqueológico de Estambul (FIRATLI 1990: 117-119, cat. nº 218-220, 223-225, con bibliografía). Con respecto a los mosaicos, el motivo aparece, entre otros, en la llamada Villa del Halconero de Argos, el mosaico de la puerta de Damasco de Jerusalén en el museo de Estambul y el mosaico de El Hammam, Beisan (ÅKERSTRÖM HougEN 1974: 64-68, con bibliografía).

16. Antiquarium de Villa Adriana, Tívoli, nº inv. 423540 (MATHEA FÖrTSCH 1999: 184, cat. 247, láms. 92,1 y 93,2; MoEsCH 2000). Del mismo modo, el motivo de las máscaras junto al de las aves picando serpientes aparece en una crátera marmórea de la misma Villa Adriana hoy en el Museo Nazionale Romano - Palazzo Massimo alle Terme $\left(n^{\circ}\right.$ inv. 1067) (SAPELLI 2001).

17. Entre los ejemplos hispánicos de época romana en los que aparecen este tipo de máscaras encontramos una columna del teatro de Segóbriga conservada en el museo de Cuenca, mostrando una máscara frontal con gorro frigio (OsUNA 1976) y la decoración del monumento funerario de Lucio Valerio Nepote en Numancia (GUTIÉRREZ BEHEMERID 1993: 157, 160-161).

18. En especial los mosaicos de Soto del Ramalete (Navarra). Para el motivo de la crátera y la profusión con la que aparece en la musivaria hispanorromana (ABÁsOLO y GARCíA 1993: 179-193; CASTELO et al. 1999: 437-438), donde se concluye que, como atributo de origen báquico, la crátera es considerada elemento benéfico, propiciatorio de fecundidad y prosperidad. 
Se observa, así mismo, cómo nos encontramos ante una tipología de crátera gallonada semejante a la que aparece en diversas muestras de la escultura hispánica tardoantigua, donde adquiere un especial protagonismo, pudiendo observar su presencia en piezas destacadas de los siglos IV-V d.C. como la cubierta de sarcófago de Ithacius de la Catedral de Oviedo, el sarcófago de la catedral de Braga, o el sarcófago de Portosín (Vidal 2005: 87-98, cat. nº. B25-B27). Este tipo de crátera difiere, sin embargo, del que encontramos en ejemplos escultóricos que han sido a menudo comparados con la pieza Amiadoso como los relieves de Gallipienzo (Navarra) (Blázquez I96I) ${ }^{19}$, a los que cabe añadir el relieve de O Saviñao (Lugo) (Varela et al. 2007). La crátera gallonada, en cambio perdurará en la escultura hispánica de los siglos VI-VII d.C. como demuestran piezas como el mencionado fuste de Beja y el fuste de La Guardia (Jaén), así como en un stipes de Sines (Portugal) o en la placa de Salvatierra de Tormes (Vidal 2005: 78-82, I80-I83, 246-247, 238-24I, cat. nº. B20, C29, $\mathrm{C}_{7 \mathrm{I}}, \mathrm{C} 68$, respectivamente). Fuera del terreno escultórico pero en la misma Gallaecia, el elemento tiene también protagonismo en las pinturas de Santa Eulalia de Bóveda (Lugo) de los siglos IV-V d.C. (Singul I999; Guardia 2003, con bibliografía), así como, algo más al sur y en un momento más temprano en las pinturas de Tróia de Setúbal de hacia el 300 d.C. (Maciel I996: 235-256, con bibliografía). Para la musivaria, uno de los ejemplos por norma general traídos a colación al hablar de este tipo de cráteras gallonadas es la lauda sepulcral en el mosaico de Baleria de la basílica de Son Peretó (Mallorca), hoy en el Museu de Manacor, datable hacia mediados/segunda mitad del siglo VI d.C. (Palol 1967: 324-325 y lám. 97; Navarro 1988: 30).

En referencia a la cronología de esta fase de la pieza, nosotros mismos aceptamos en su momento la datación tradicionalmente propuesta por los estudiosos que la sitúa en el siglo II d.C. (Vidal 2005: 6, nota 3). Observamos sin embargo, que la mayor parte de los paralelos propuestos parecen remitirnos a un momento posterior, dentro ya del periodo tardorromano, concretamente al siglo IV d.C. La calidad del relieve principal de la cara frontal, a pesar del desgaste de su superficie, parecería propia de un momento altoimperial, en consonancia con la rica tradición figurativa de ese periodo con claras raíces helenísticas. Por el contrario el lateral derecho con la crátera y el roleo con máscara, cuyo relieve presenta un mejor estado de conservación, posee unas características figurativas más propias de la plástica bajoimperial, con una datación que plausiblemente debemos situar en el siglo IV d.C., fecha a la que cabría asignar esta primera fase de la pieza.

19. Para su comparación con la pieza de Amiadoso ver NúÑEZ Rodríguez (1976: 185-186, nota 5; Id., 1978: 99100). A los relieves de Gallipienzo cabe sumar el ejemplar de la villa de los Torrejones de Yecla (Murcia) del Museo de Murcia y la estela funeraria de Luzcano (Álava) del Museo Arqueológico de Vitoria, todos ellos datados de manera aproximada en el siglo IV d.C. (PALOL 1967: 241, láms. LIII-LV). Datadas ya en la segunda mitad del siglo IV d.C., encontramos las placas de revestimiento de la villa do Rabaçal en Penela (Portugal) (PESSOA y STEINERT 2001, con bibliografía). 


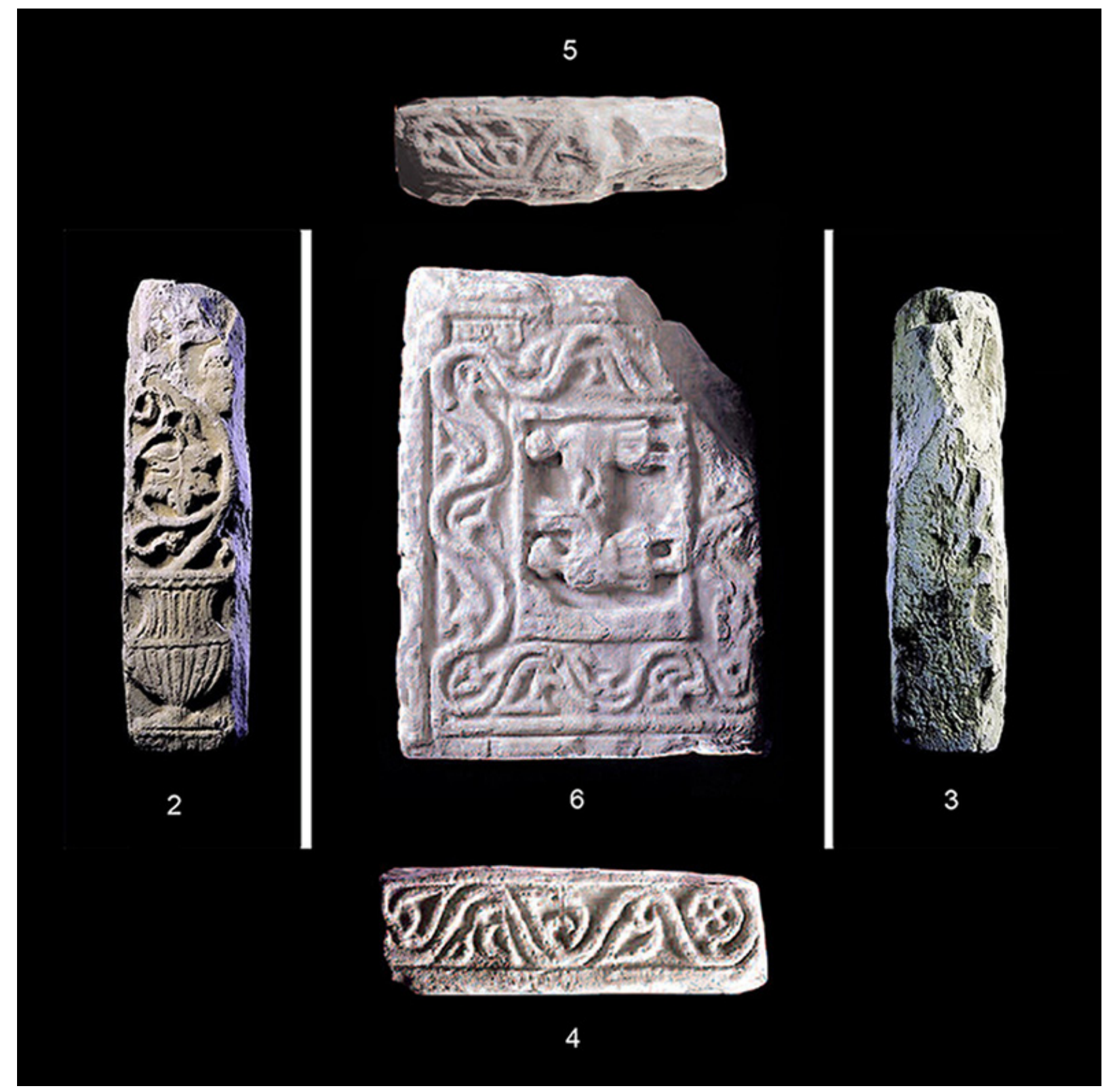

FIGURA 3. IMAGEN COMPUESTA DE LAS DIFERENTES CARAS DECORADAS EN RELIEVE DE LA PLACA DE AMIADOSO. FASE II (MONTAJE A PARTIR DE LAS FOTOGRAFÍAS DE CERES).

\section{II.2. FASE 2: PERIODO PRERROMÁNICO O ROMÁNICO}

Las tres caras restantes de la pieza presentan un tipo de decoración escultórica que difiere de las anteriores, mostrando una talla de las superficies más sumaria y una configuración de los motivos más esquemática (Figura 3). En esta segunda fase la pieza original es recortada por su extremo superior, quedando truncados los motivos vegetales antes descritos, girando su orientación $90^{\circ}$ a izquierda, con lo que 
pasa de ser vertical a horizontal. En esta fase se configura una nueva cara principal -que corresponde al reverso del motivo vegetal principal de la fase anterior- y los dos laterales de esta última -correspondientes a los extremos superior e inferior de la pieza en su orientación original-. Ambos costados se decoran con un sencillo roleo vegetal de tallo ondulante, rematado por sencillas hojas piriformes huecas, quedando rematada en un extremo del costado derecho, por una sencilla rosácea circular de cuatro pétalos. El perímetro de la cara principal se decora igualmente mediante un roleo de similares características, con hojas de distintos tamaños, que enmarca un cuadro central en el que aparecen dos personajes afrontados. Éstos visten sendas túnicas cortas ceñidas a la cintura y muestran los brazos extendidos, hacia delante en el caso del personaje de la derecha y hacia arriba el de la izquierda. Detrás de este último parece haber un grueso elemento vertical que ocupa el extremo izquierdo y el ángulo superior de la escena.

La escena ha suscitado diversas interpretaciones, entre las que encontramos la de J. Lorenzo Fernández, de que pudiera tratarse de una escena de ofrenda de una iglesia, o la de I. Bango que la interpreta como una posible Ascensión de Cristo (Lorenzo Fernández I953; Bango 1987: 36). Según esta última, de la figura de Cristo se representarían únicamente los pies, situándose en la zona superior central, entre ambos personajes; sin embargo, creemos que esta hipótesis debe ser descartada ya que éste no se trata de un elemento exento, correspondiendo, como se ha indicado, a los brazos extendidos (hacia arriba) de la figura izquierda. Dado el carácter esquemático de las figuras y la rudeza de la talla es difícil proporcionar una identificación iconográfica inequívoca de la pieza, siendo amplio el elenco de escenas bíblicas/con trasfondo religioso protagonizadas por dos figuras enfrentadas. Podemos considerar que una parece estar entregando algo a la otra a modo de traditio, pero ni siquiera este extremo es claro, como tampoco lo es el género de los personajes, en especial el de la izquierda, cuyo peinado podría corresponder al de una mujer, por poseer mayor volumen. En tal caso, no debería descartarse la posibilidad de encontrarnos ante alguna escena protagonizada por la Virgen María ${ }^{20}$.

Creemos interesante recalcar el dato de que el tipo de figuración de este relieve nos remite de un modo directo a la que presentan otros ejemplares gallegos datados grosso modo en un momento altomedieval, anterior al románico (ca. siglos IX-X), directamente relacionables, por tanto, con la época de la monarquía Astur o con la pervivencia de sus pautas escultóricas en un momento inmediatamente posterior. De un modo especial cabe hacer mención, tal y como muchos otros estudiosos han hecho, de la pareja de relieves procedentes de San Xoán de Camba (Ourense), conservados en el Museo Provincial de Ourense (Barriocanal López i99ia; Yzquierdo Perrín 1993: I52-I53; Conde Sánchez 200I; Barriocanal López 2012). En ellos se

20. Entre otros, temas como la Anunciación y la Visitación hacen acto de presencia en la escultura ya a inicios del siglo V d.C., como demuestra el sarcófago de los Pignatorum en el Braccioforte de Rávena (KoLLWITz y Herdejürgen 1979: 54-57, 105-114, cat. $n^{\circ}$ B1). Más dudosa es, sin embargo, la presencia de la escena de la Anunciación en el caso hispánico del Sarcófago de Cameno (Burgos) (VIDAL 2005: 46-48, cat. B4), mientras que este mismo tema está ya claramente presente en la escultura hispánica altomedieval en ejemplos como el capitel de Sant Benet de Bages (Barcelona), datado en el 972 (BArRal i Altet 1984: 431, 437-438; Arbeiter y NoACK Haley 1999: 412, con la bibliografía anterior). 
observa un tipo de figuración semejante a la de Amiadoso, si bien, con un acabado de las figuras algo más rudo, lo que queda agravado por el material empleado, granito. Uno de los relieves representa una epifanía, mientras que el segundo muestra dos escenas interpretadas bien como un posible sacrificio de Isaac a la izquierda y una escena protagonizada por Cristo (posible Bautismo) a la derecha, o bien como dos escenas consecutivas alusivas a la Resurrección de Cristo. A este grupo de relieves ourensanos con semejantes características figurativas, pertenece también el relieve (¿imposta?) procedente de San Martiño de Pazó, conservado en el Mismo Museo Provincial, representando un personaje orante junto a una esquemática hoja de acanto (Barriocanal López I99Ib; Yzquierdo Perrín I993: I22-I23; Veiga Romero 2005; Barriocanal López 20I2). El grupo se completa con los relieves situados a ambos lados de la fachada de la iglesia de San Xes (San Ginés) de Francelos (Ourense), entre los que destaca la escena de la entrada de Cristo en Jerusalén, siendo su datación más comúnmente aceptada en torno al año 900 (Núñez Rodríguez I978: I69-I78; Yzquierdo Perrín I993: 99-105).

Para la datación de esta segunda fase, además de los paralelos ya presentados, debemos hacer también mención de los dos relieves procedentes del mismo edificio de San Adrián de Amiadoso, conservados en el Museo Provincial de Ourense, con sendas cruces de tradición asturiana, es decir, cruces griegas de brazos patados con el centro circular y las letras alfa y omega colgando de los brazos horizontales, como símbolo del Reino de Asturias, cuya factura ha sido puesta en relación con la época de Alfonso III (866-9Io) (Acuña Fernández y Valle Pérez I99I; Yzquierdo Perrín I993: 152, entre otros).

\section{ASPECTOS ARQUEOMÉTRICOS: UN TESTIGO DE LA INDUSTRIA LOCAL DEL MÁRMOL}

\section{III.1. PLANTEAMIENTO Y METODOLOGÍA APLICADA}

El objetivo del estudio arqueométrico ha sido la caracterización litológica del mármol con el que se elaboró esta pieza, con la finalidad de indagar sobre la procedencia local o foránea de este material lítico. Como ha sido ya ampliamente demostrado, la identificación de los mármoles empleados en época antigua no es posible mediante la aplicación de una sola técnica analítica. Ésta debe ser abordada con estudios mineralógicos y geoquímicos, aplicados doblemente en las piezas arqueológicas objeto de la investigación y en muestras de cantera, referencia imprescindible para identificar el origen de las primeras. Si bien la aplicación de estas técnicas es deseable en la mayoría de los materiales, en el caso de los mármoles blancos se hace imprescindible puesto que las características macroscópicas no son suficientemente discriminantes. Evidentemente, esta caracterización resulta más completa cuantas más técnicas se apliquen (estudio multi-método), valorando los resultados de varios análisis. 
En el caso de la placa de Amiadoso, ha sido necesario realizar lo que podríamos denominar como un doble estudio: por un lado la caracterización litológica de la pieza per se y, paralelamente, la ampliación de la base de referencia necesaria con la incorporación de muestras de canteras gallegas para comparar los resultados de ésta, dado que una de las hipótesis a priori indicaba que podría haberse empleado un mármol local para su elaboración. Así, a pesar de que la litoteca de referencia sobre los mármoles de canteras hispanas se ha visto ampliada sustancialmente en los últimos años (Lapuente et al. 2000; Lapuente et al. 20I4), el vacío existente respecto a los materiales del noroeste hizo imprescindible llevar a cabo la localización y estudio de afloramientos marmóreos en el territorio gallego susceptibles de haber sido explotados en la antigüedad.

Tras una primera observación ocular del mármol que conforma la pieza, se

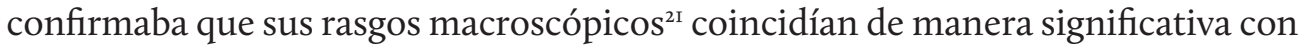
el mármol de $\mathrm{O}$ Incio, considerado habitualmente como una caliza marmórea y tradicionalmente asociado a una serie de objetos de factura tardoantigua. No obstante, hasta el momento no se podía conocer con certeza su procedencia exacta, a falta de una caracterización arqueométrica de esta variedad. Por ello fue necesaria la localización de las principales canteras de explotación de este mármol, que se encuentran principalmente en el ayuntamiento del que toma su nombre, $\mathrm{O}$ Incio (provincia de Lugo).

La explotación de este mármol se conoce con certeza al menos desde el siglo XII ya que la singular iglesia de $\mathrm{S}$. Pedro Félix de Hospital de O Incio fue íntegramente construida en ese material por la Orden de Jerusalén ${ }^{22}$. En realidad, los afloramientos en los que existen claras evidencias de extracción se sitúan en torno al lugar de $\mathrm{O}$ Hospital y Pacios. En ambos casos se trata de pequeñas explotaciones abiertas en la formación geológica del Cámbrico Inferior conocida como Calizas de Cándana (Zona Asturoccidental-Leonesa) principalmente compuesta por rocas calizas y dolomíticas que en la Orogenia Hercínica fueron afectadas por un metamorfismo regional que de manera irregular transformó algunos de estos materiales en mármoles de grano fino. No obstante, ambas canteras estuvieron en activo a mediados del siglo pasado y actualmente se encuentran cubiertas por una densa vegetación, hecho que hace difícil llegar a distinguir zonas con posibles evidencias de trabajo antiguo de aquellas zonas de explotación reciente. Así pues, todos los frentes fueron sistemáticamente muestreados para cubrir toda la gama de variación observada que presenta el mármol ${ }^{23}$ y, los resultados del análisis arqueométrico de estas muestras

21. Como ya se ha apuntado, se trata de un mármol de grano fino, bien cristalizado y en el que se alternan bandas blancas y grises prácticamente formando una laminación (vid. supra).

22. Sobre la fecha de construcción de esta iglesia, aunque se menciona el 1130 (GonZÁLEZ SÁNCHEZ 1992: 241), la mayoría de los autores, como aparece reflejado en López Lombo (2003: 30-31, 63, 130) y en la Gran Enciclopedia Gallega (2003: T. 23, 142. Voz «Hospital»), indican que la construcción de esta iglesia debió llevarse a cabo hacia finales del s. XII d.C. (posiblemente hacia 1180-1190). Dicha iglesia fue declarada monumento histórico-artístico en 1981, declaración posteriormente completada con su entorno en 1997.

23. A partir de los rasgos macroscópicos y microscópicos se distinguen 3 variedades, que fueron presentadas varios congresos internacionales (GonzÁlez SOUtelo et al. 2015; GUTIÉRREZ GARCIA-M. et al. 2014). 
han sido introducidos en nuestras bases de datos de referencia (Gutiérrez Garcia-M. et al. en prensa -b) ${ }^{24}$ para ser cotejados con el mármol de la placa de Amiadoso.

Para el estudio de esta pieza, se ha seguido un protocolo de estudio multimétodo consistente en la combinación del análisis petrográfico macroscópico y microscópico. El análisis macroscópico se ha efectuado mediante observación ocular directa de la pieza, permitiendo evaluar rasgos globales del mármol tales como el color y tonalidades, presencia de veteados o laminaciones, brillo y transparencia, homogeneidad del tamaño de grano y presencia de puntos de alteración ${ }^{25}$. A nivel microscópico, se han realizado análisis por microscopía óptica de luz polarizada y catodoluminiscencia $(\mathrm{CL})$, complementándose con el análisis geoquímico de isótopos estables de carbono y oxígeno $\left(\delta^{13} \mathrm{C} \text { y } \delta^{18} \mathrm{O}\right)^{26}$.

Los resultados obtenidos se han comparado con muestras de referencia de los principales tipos de mármoles utilizados en época romana depositadas en el Laboratorio para el Estudio de Materiales Lapídeos en la Antigüedad (LEMLA) y en la colección de muestras depositadas en el ICAC, así como con las bases de referencia publicadas de las más importantes fuentes de extracción de la cuenca mediterránea explotadas en la Antigüedad (Gorgoni et al. 2002; Attanasio et al. 2006; Lapuente et al. 20I4; Antonelli y Lazzarini 2015).

\section{III.2. RESULTADOS E INTERPRETACIÓN}

Esta pieza está elaborada con un mármol bandeado blanco y gris claro, de grano fino. El estudio petrográfico permite caracterizarlo como un mármol puro de composición calcítica (más de un 95\% de minerales carbonatados, y entre ellos, más de un 90\% de calcita), fábrica ligeramente anisótropa marcada por una sutil orientación de sus cristales y textura heteroblástica con un tamaño de grano fino, heterométrico y tamaño máximo de grano (MGS) de I,3 mm. Los cristales presentan una buena cristalización con contactos predominantemente suturados e interpenetrados. Se encuentran distribuidos uniformemente y presentan numerosas

24. En posteriores revisiones hemos podido completar el inventario de afloramientos de mármol o caliza marmórea en el mismo ayuntamiento, dentro de las parroquias de Sta. Ma de Mao, O Viso, Vila de Mouros, S. Pedro do Incio, y S. Pedro Fiz do Hospital, aunque no siempre se ha podido confirmar la presencia de frentes de cantera. Las muestras tomadas en estos lugares están en proceso de estudio.

25. A ser evitados en el momento de la toma de muestra para el análisis arqueométrico.

26. Los análisis microscópicos requirieron la preparación de una lámina delgada, realizada en el Laboratorio de Preparación de Láminas Delgadas del Departamento de Geología de la Universitat Autònoma de Barcelona (UAB). La lámina delgada, sin cubrir, presenta un grosor de $30 \mu \mathrm{m}$, y ha sido teñida, en parte, mediante el colorante Rojo de Alizarina-S. Los análisis petrográficos y por catodoluminiscencia han sido llevados a cabo en la Unidad de Estudios Arqueométricos (UEA) del Institut Català d'Arqueologia Clàssica (ICAC). En las observaciones con la lupa binocular se ha utilizado una lupa ZeissStemi 2000-C y para las descripciones microscópicas se ha utilizado un microscopio de luz polarizada Nikon Eclipse 50i POL, a 30x, 60x y 150x, con un dispositivo acoplado Citl CL8200 Mk5-1 para el estudio de la catodoluminiscencia. Para las fotografías se ha utilizado una cámara Nikon CoolPix 5400. El análisis isotópico se ha realizado en el Laboratorio di Isotopi stabili del Istituto di Geologia Ambientale e Geoingegneria (IGAG-CNR) en Roma (por M. Brilli, a quién queremos agradecer su colaboración), con un espectrómetro de masas de relaciones isotópicas-IRMS GasBench II, previa preparación de la muestra (pulverización de mínimo 1 gr del material a analizar). Los resultados se expresan en notación delta $(\delta)$ habitual $\delta^{13} \mathrm{C}$ and $\delta^{18} \mathrm{O}$ mediante la relación de esta proporción en la muestra, en tantos por mil (\%o) respecto al estándar internacional PDB (Pee Dee Belemnite). 
exfoliaciones y maclas bastante bien formadas, gruesas y tabulares. De manera ocasional se observan cristales con maclas ligeramente deformadas junto con algún cristal aislado que presenta una sutil extinción ondulante que son signos de la existencia de una deformación intracristalina poco desarrollada. Como minerales accesorios presenta un I\% de pequeños cristales de cuarzo con un tamaño máximo de $0,2 \mathrm{~mm}$, subredondeados, aislados o formando pequeños agregados, tanto rodeados por cristales de calcita como incluidos en ellos. Este mármol presenta una catodoluminiscencia homogénea con una intensidad media y tonalidad rojiza anaranjada, particularmente con los límites intercristalinos marcados por una luminiscencia de mayor intensidad, resaltando el cuarzo accesorio no luminiscente (Figura 4).

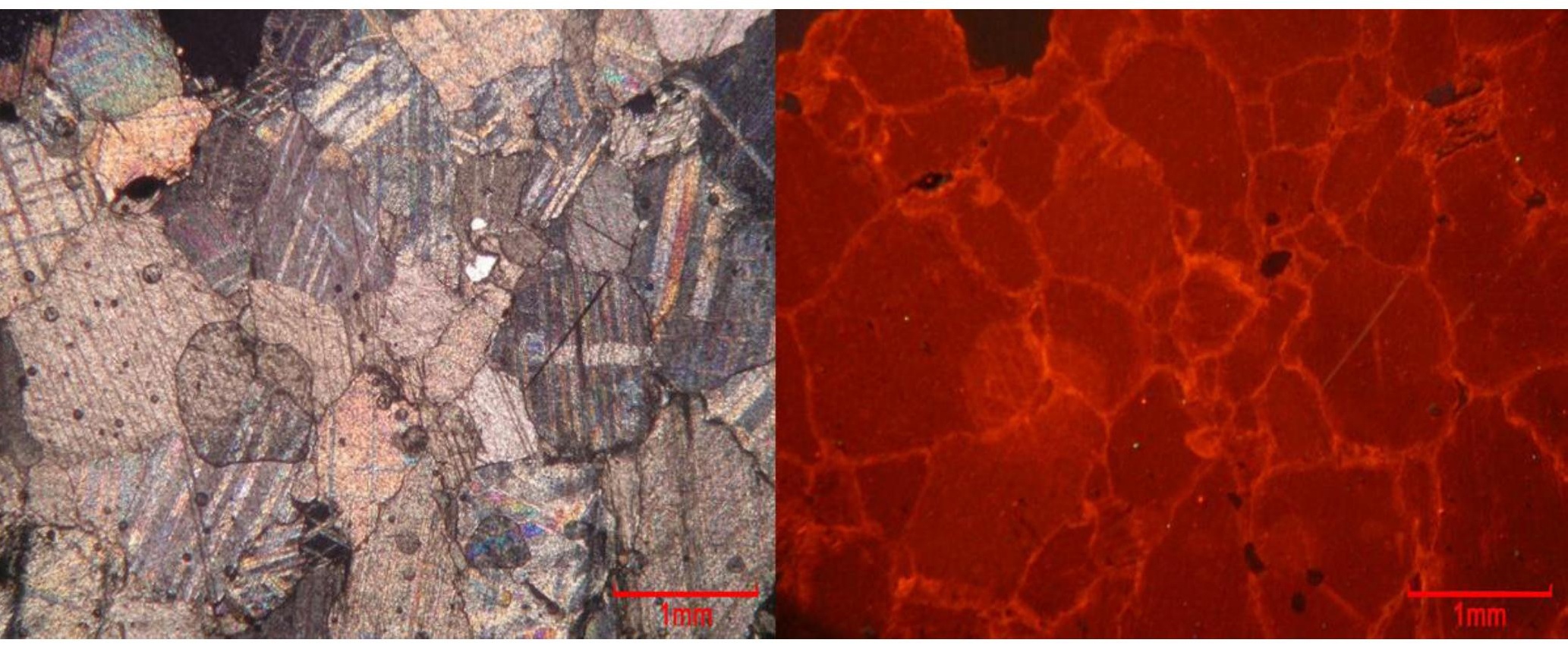

FIGURA 4. MICROFOTOGRAFÍA DE LA MUESTRA OUR-0859, OBTENIDA DE LA PLACA DE AMIADOSO: CON ANALIZADOR POLARIZADO (IZQUIERDA) Y CON CATODOLUMINISCENCIA (DERECHA). (Foto: H. Royo).

En cuanto a su caracterización isotópica, este material presenta un valor isotópico positivo en $\delta^{13} \mathrm{C}$ de $0,3 \%$ y un valor negativo en $\delta^{18} \mathrm{O}$ de $-15,2 \%$. Estos valores la sitúan en el límite del campo de referencia obtenido para O Incio a partir de las muestras de cantera (Gutiérrez Garcia-M. et al. en prensa -b) ${ }^{27}$ (Figura 5).

El cotejo de esta muestra con los principales mármoles blancos de las colecciones de referencia LEMLA e ICAC descarta una procedencia foránea para este material. La hipótesis avanzada en las primeras fases del proceso analítico, que apuntaba a un tipo de mármol bandeado local, posiblemente de $\mathrm{O}$ Incio, parece verse reforzada

27. Los valores de esta pieza deben tomarse con cierta precaución y han de ser valorados de forma conjunta con los datos petrográficos y de catodoluminiscencia, dado que el estado de la superficie de la propia pieza no permite descartar completamente una posible ligera alteración de la muestra. 


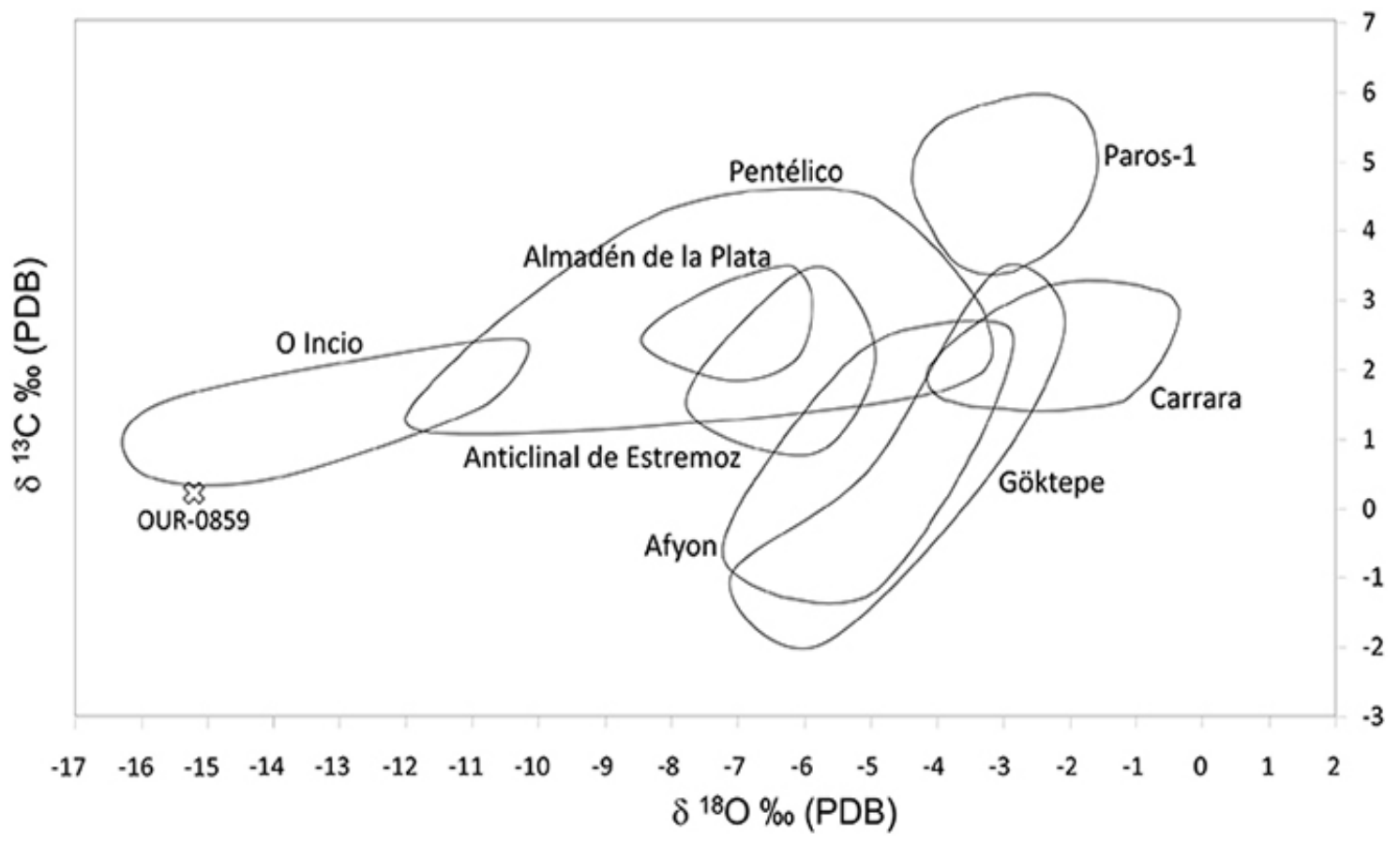

FIGURA 5. DIAGRAMA QUE PRESENTA LOS VALORES ISOTÓPICOS $\delta^{13} \mathrm{C} Y \delta^{18}$ O DE LA MUESTRA OUR-O859, JUNTO CON LOS CAMPOS DE DISTRIBUCIÓN DE LOS MÁRMOLES, HISPANOS (LAPUENTE ET AL. 2OI4; GUTIÉRREZ GARCIA-M. ET AL. EN PRENSA -B) Y CLÁSICOS (GORGONIET AL. 2002 ; ATTANASIO ET AL. 2009), DE COMPOSICIÓN Y TAMAÑO DE GRANO COMPATIBLES.

por el resultado del análisis de sus relaciones isotópicas de $\mathrm{C}$ y $\mathrm{O}$. En cuanto a las características petrográficas de la muestra, se asemejan pero no acaban de coincidir completamente con las presentadas por las muestras de referencia de estas canteras. Lo mismo sucede con la respuesta a la CL, y aunque por otro lado, ésta coincide significativamente con la de la variedad bandeada de mármol de Estremoz (Portugal), los valores isotópicos caen significativamente lejos del campo de distribución de éste mármol portugués ${ }^{28}$. Así, los datos obtenidos para esta pieza parecen indicar que se trata de un material local, presente en el NO peninsular, cuyo punto de origen exacto aún no ha sido localizado. A pesar de que no se ha obtenido una correspondencia perfecta con el mármol de O Incio, el origen del mármol empleado para esta placa está muy posiblemente relacionado con los afloramientos de mármol explotados en las canteras de O Incio o en sus inmediaciones, asociados a la Formación Calizas de Cándana (Zona Asturoccidental-Leonesa), siendo menos probable su relación con las canteras presentes en la prolongación de dicha formación por la actual provincia leonesa (Cisneros et al. 20I0-20Ir: 96-IOI), dónde los litotipos existentes

28. Aunque el campo de distribución publicado hasta la fecha corresponde a las variedades blancas (LAPUENTE et al. 2000, 2014), según los resultados presentados recientemente en el XI Congreso ASMOSIA (Split), los litotipos grises y bandeadas presentan valores que no varían significativamente. Queremos agradecer a P. Lapuente sus consideraciones al respecto, a la espera de la publicación de este trabajo (LAPUENTE et al. en prensa). 
presentan ya de entrada unas características macroscópicas bastante alejadas de las de nuestra placa.

\section{CONSIDERACIONES FINALES}

Como ya se ha visto en la revisión bibliográfica, al margen de las diferentes interpretaciones iconográficas que puede suscitar la pieza y de la ambigüedad cronológica que presentan ambas fases, es evidente afirmar que dicha bipolaridad existe y que la pieza posee dos momentos de uso claramente diferenciados. Creemos poder proponer que en un primer momento, por su morfología, la pieza parece corresponder bien a una lesena (semipilastra adosada a un muro) o bien a una jamba, en todo caso, a un elemento de escaso grosor de formato eminentemente vertical, con una de sus caras principales adosada a un muro. Su decoración es de carácter profano, con los paralelos señalados más arriba, y se enmarca perfectamente dentro de la tradición romana de elementos arquitectónicos decorados con temas vegetales.

Por el contrario, en un segundo momento, la pieza no solo ha perdido su contexto arquitectónico original, sino que ha sido cortada por su extremo superior para ser reutilizada, posiblemente, como placa de cancel de pequeñas dimensiones, que aúna la temática vegetal (a interpretarse en clave escatológica) con temática verosímilmente bíblica. Dada la altura original que pudo alcanzar la pieza, es probable que en su reutilización hubiera podido proporcionar cuanto menos un segundo cancel, que desconocemos, haciendo pareja con el anterior, con el frente decorado con un segundo tema bíblico (complementario del primero).

En referencia al edificio de San Adrián de Amiadoso al que perteneció la pieza, se trataría de una pequeña construcción rectangular, de nave única, datada entre los siglos IX-X d.C., cuyos escasos restos conservados cumplen hoy la función de garaje (Sánchez Pardo 2015: 98). No existe un acuerdo sobre la existencia y definición de sus posibles fases constructivas más antiguas, yendo las hipótesis desde un supuesto mausoleo tardorromano del siglo IV d.C., a una posible construcción eclesiástica de época visigoda 0 «mozárabe $»^{29}$. En todo caso, parece lógico relacionar la segunda fase del relieve con el edificio de época altomedieval, mientras que para la primera fase de los relieves, es precisamente nuestra pieza la base sobre la que se han sustentado las mencionadas propuestas y posibles dataciones. La pieza pudo ser obviamente trasladada desde otro lugar (seguramente cercano), para ser reutilizada en época altomedieval, con lo que carecemos de datos fehacientes que nos ayuden a concretar más en este sentido.

La confirmación mediante análisis arqueométricos de que el mármol empleado en la elaboración de la pieza de Amiadoso pertenece a una variedad de mármol relacionada muy probablemente con la zona de O Incio (Lugo), ya sugerido por diversos autores (Fariña Busto 2004), es un paso importante en el estudio de esta

29. Ver SÁNCHEZ PARDO 2012b: 402, recogiendo las principales hipótesis y la bibliografía al respecto, y SÁNCHEZ PARDO 2015: 98. 
pieza ya que nos permite confirmar el carácter local tanto de su procedencia como del taller que realizó sus relieves. Este dato que, si bien podría parecer obvio para la fase altomedieval de la pieza, es mucho más revelador a la hora de valorar los relieves de la primera fase, planteando la necesidad de reconsiderar y reflexionar sobre al menos dos aspectos fundamentales:

* Por una parte, la proximidad de la extracción y por lo tanto su producción local. Si bien este dato no da lugar a sorpresa para la fase altomedieval de la pieza, aporta un sólido argumento al estudio de los relieves de la primera fase, dada su calidad y buen acabado técnico.

* Por otra parte, la existencia de un taller de producción activo en este ámbito al menos desde el s. IV d.C. (tal y como apunta el análisis estilístico), se podría relacionar con otras piezas locales, tales como el sarcófago de Portosín, la placa de O Saviñao, la cubierta del sarcófago de Ithacius de la Catedral de Oviedo, o los relieves del Palacio de Revillagigedo de Gijón ${ }^{30}$.

Asimismo, dado que consideramos que la pieza debería encuadrarse en el s. IV d.C., esta combinación de datos arqueométricos y estilísticos nos permite ratificar la propuesta de que si bien es cierto que conocíamos la explotación de una de las variedades del mármol conocido como «mármol de O Incio» ya en el siglo XII d.C., las evidencias cada vez más abundantes de la existencia de un mayor número de objetos constructivos de pequeño tamaño realizados en este material ya en época romana (Gutiérrez Garcia-M. et al. en prensa-a), nos habla de la estabilización de una tradición local de talleres escultóricos de fuerte presencia en Galicia ya desde al menos el s. IV d.C., que pervivirá en siglos posteriores, como nos indican los nuevos datos vinculados a piezas datadas en el s. VI-VII d.C., como los capiteles de S. Comba de Bande, así como en el caso de los capiteles de S. Xoán de Campos y algunas de las piezas atribuidas al taller de Setecoros (Domingo 2011: 92-93).

Estamos, por tanto, ante una muestra excepcional de la realidad escultórica desarrollada en el noroeste peninsular al menos desde el siglo IV d.C., en la que aparece asociada toda la cadena productiva para la elaboración de ésta y otras piezas constructivas y ornamentales realizadas con el material lapídeo más significativo de este territorio. De ahí que, de acuerdo con éste y otros ejemplos, nos encontraríamos ante una producción especializada tanto desde la extracción del material marmóreo (normalmente piezas de no excesivo tamaño y normalmente con función arquitectónica), como en el caso de la realización escultórica y ornamental de la pieza, sorprendiendo, al menos para esta primera fase, por su calidad en cuanto a formas y acabados, según los modelos habituales del mundo romano.

Esa calidad se transforma ya en el s. IX-X, en la segunda fase o vida de la pieza, donde su representación peca en su baja calidad formal y esquematismo, reformando

30. Para las piezas de Portosín, Oviedo y Gijón ver VIDAL 2007 con la bibliografía anterior y VIDAL y GARCíAENTERO 2015 y VIDAL et al. 2016 e.p. para resultados arqueométricos de, entre otras, las piezas asturianas. Para la placa de O Saviñao ver VARELA et al. 2007. 
una de las caras de esta singular pieza, que a partir de ser reorientada y reutilizada con una función aún no bien definida, pasa a formar parte de las representaciones vinculadas ya al ámbito altomedieval cristiano.

Entender las causas de su reutilización pasa por establecer propuestas que van desde un proceso de cristianización de un elemento pagano, la necesidad de reaprovechar piezas precedentes de calidad que resalten distintos ámbitos del culto eclesiástico y del mundo clásico, el propio interés de estas piezas o bien su elevado coste, así como la falta de materiales o talleres que permitiesen la creación de nuevas formas y nuevos productos ${ }^{3}$.

Aunque no es objeto de este estudio entrar a considerar esa problemática, cabe llamar la atención sobre los múltiples aspectos que un estudio interdisciplinar puede suscitar para la comprensión de dichos objetos, ya no solo como piezas singulares en sí mismas, sino como claves para la interpretación y aproximación del contexto en el que surgieron y en el que se desarrollaron, en donde las conclusiones derivadas de éste y otros estudios sobre los materiales marmóreos en Galicia esperamos puedan aportar un nuevo enfoque a esta problemática.

31. Sobre esta temática ver los últimos trabajos de Utrero Agudo y SAStre de Diego 2013; Sánchez Pardo 2015, entre otros. 


\section{BIBLIOGRAFÍA}

AA.VV. I992: Imaxes da Arte en Galicia, catalogación arqueolóxica e artística de Galicia do Museo de Pontevedra. Cuaderno-Catálogo (Lugo, Xuño i992). Lugo.

ABÁSOlO, J.A. y GARcíA, R. I993: Excavaciones en Sasamón (Burgos). Excavaciones Arqueológicas en España I64. Madrid.

Acuña Fernández, P. y Valle Pérez, J.C. I99i: «Pilastra de Amiadoso». Galicia no Tempo. Santiago de Compostela: II9-I20, $\mathrm{n}^{\mathrm{O}} 23$.

Åkerström Hougen, G. I974: The Calendar and Hunting Mosaics of the Villa of the Falconer in Argos. Stockholm.

Àlvarez, A., Domènech, A., Lapuente, M.P., Pitarch, A. y Royo, H. 20oga: Marbles and stones of Hispania. Exhibition catalogue. Tarragona.

Àlvarez, A., García-Entero, V., Gutièrrez Garcia-M., A. y RodĀ, l. 20ogb: El marmor de Tarraco. Explotació, utilització i comercialització de la pedra de Santa Tecla en època romana. Tarragona.

Antonelli, F. y LAZZARINI, L. 2015: «An updated petrographic and isotopic reference database for White marbles used in antiquity», Rendiconti di Science Fisiche. Accademia dei Lincei 26: 399-4I3.

Arbeiter, A. y Noack-Haley, S. I999: Hispania Antiqua. Christliche Denkmäler des frühen Mittelalters, Vom 8.bis ins II. Jahrhundert. Mainz am Rhein.

Arce, J. I973: «Fuste de columna visigodo inédito del Museo Arqueológico de Jaén». XII Congreso Nacional de Arqueología. Zaragoza: 79I-796.

Arias Vilas, F. I992: A romanización de Galicia. Vigo.

Attanasio, D., BRilli, M. y OGle, N. 2006: The isotopic signature of classical marbles, Studia Archaeologica I45. Roma.

Attanasio, D., Bruno, M. y Yavuz, A.B. 2009: "Quarries in the region of Aphrodisias: the black and white marbles of Göktepe». Journal of Roman Archaeology 22 (I): 3I2-348.

Bango Torviso, I. I987: Galicia Románica. Vigo.

Barral i Altet, X. I984: «Sant Benet de Bages», Catalunya Romànica XI, El Bages. Barcelona: 408-438.

Barriocanal López, Y. i99ia: «Relieves de Camba», Galicia no Tempo. Santiago de Compostela: I83-I84.

Barriocanal López, Y. i99ib: «Relieve de Pazó», Galicia no Tempo. Santiago de Compostela: I8O.

BARriocanAl López, Y. 20I2: «Memoria, culto y ornato en la Gallaecia astur-leonesa (III)». Gallecia Petrea. Santiago de Compostela: 357.

Blázquez, J.M. I96r: «Relieves de los 'Casquilletes de San Juan', Gallipienzo». Príncipe de Viana 84-85: I2I-I26.

Camporeale, S., Dessales, H. y Pizzo, A. (eds.) 2008: Arqueología de la construcción I. Los procesos constructivos en el mundo romano: Italia y provincias occidentales. Anejos del Archivo Español de Arqueología 50. Madrid-Mérida.

Camporeale, S., Dessales, H. y Pizzo, A. (eds.) 20io: Arqueología de la construcción II. Los procesos constructivos en el mundo romano: Italia y provincias orientales. Anejos del Archivo Español de Arqueología 57. Madrid-Mérida. 
Camporeale, S., Dessales, H. y Pizzo, A. (eds.) 20iz: Arqueología de la construcción III. Los procesos constructivos en el mundo romano: la economía de las obras. Anejos del Archivo Español de Arqueología 64. Madrid-Mérida.

Camporeale, S., Dessales, H. y Pizzo, A. (eds.) 20I4: Arqueología de la construcción IV. Las canteras en el mundo antiguo: sistemas de explotación y procesos productivos. Anejos del Archivo Español de Arqueología 69. Madrid-Mérida.

Castelo Ruano, R., Arribas Domínguez, R., Panizo Arias, I., Torrecilla Aznar, A. y López Pérez, A. I999: «Los pavimentos musivarios de la Villa de El Saucedo (Talavera la Nueva, Toledo)». XXIV Congreso Nacional de Arqueología vol. IV. Murcia: 435-455.

CastiÑEiras GonZÁlez, M. I990: «La reutilización de piezas romanas y medievales en Galicia». Brigantium 6: 77-90.

Cisneros Cunchillos, M., Gisbert Aguilar, J. y Somovilla de Miguel, l.A. 20io-20it: «El uso del mármol en la arquitectura de Asturica Augusta». Anales de Arqueología Cordobesa 2I-22: 93-I26.

Conde SÁnchez, M. 20oI: «Relevo da Epifanía. San Xoán e Camba, Castro Caldelas». Museo Arqueolóxico de Ourense, Peza do Mes I2/20oI. Ourense.

Domingo MagaÑA, J. 20II: Capiteles tardorromanos y visigodos en la península Ibérica (siglos IV-VIII d. C.). Tarragona.

FARIÑA Busto, F. I99I: «De la prehistoria a la romanización». Imaxes da Arte en Galicia, catalogación arqueolóxica e artística de Galicia do Museo de Pontevedra. A Coruña: 29-57.

FARIÑA Busto, F. I997: «Amiadoso». Galicia castrexa e romana. Galicia Terra Única. Lugo: 3I3-3i6.

FariÑa Busto, F. 2004: «Placa decorativa de Amiadoso». Museo Arqueolóxico de Ourense, Peza do Mes 0I/2004. Ourense.

Firatli, N. I990: La sculpture byzantine figurée au Musée Archéologique d'Istanbul. Paris.

Gamer, G. I970: «Die Rankensäule in Beja/Portugal». Madrider Mitteilungen II: I29-I38 y láms. 3I-34.

GAMER, G. I97I: «Les colonnes ornées de pampes et la colonne de Beja». Actas do Il Congresso Nacional de Arqueologia, Vol. Il. Coimbra: 487-493.

García-Entero, V. (ed.) 20I2: El marmor en Hispania: explotación, uso y difusión en época romana. Madrid.

Giuliano, A. (ed.) I985: Museo Nazionale Romano. Le Sculture, vol. 1/8. Roma.

GonZÁLEZ SÁNCHEZ, J.M. I992: «Las órdenes militares y la labor asistencial en el Camino de Santiago, Hospital de San Pedro Félix de Incio». En H. Santiago (ed.): El Camino de Santiago: la hospitalidad monástica y las peregrinaciones. Valladolid: 24I-248.

González Soutelo, S., Gutiérrez Garcia-M., A. y Royo Plumed, H. 2015: «El mármol de O Incio: proyecto de caracterización y estudio de la explotación y uso de un marmor local en la Galicia romana». XVIII Congreso Internacional de Arqueología Clásica, Mérida:323-326.

Gorgoni, C., Lazzarini, L., Pallante, P. y Turi, B. 2002: «Anupdated and detailed minero petrographic and $\mathrm{C}-\mathrm{O}$ stable isotopic reference database for the main Mediterranean marbles used in antiquity». En J. Herrmann, N. Herz y R. Newman (eds.): Proceedings of the Fifth International Conference of the ASMOSIA. London: II5-I3I.

GRAN ENCICLOPEDIA GALLEGA 2003: «Hospital». T. 23: 142.

GuARDIA, M. 2003: «El santuario romano de Bóveda y su ornamentación pictórica». Semata I4: $253-276$.

Gutiérrez Behemerid, M. A. 1993: «El monumento funerario de Lucio Valerio Nepote de Numancia». Boletín del Seminario de Arte y Arqueología 59: 155-166. 
Gutiérrez Garcia-M., A., Lapuente, P. y RodÀ, I. (eds.) 20I2: Interdisciplinary Studies on Ancient Stone, Proceedings of the IX ASMOSIA Conference. Tarragona.

Gutiérrez García-M., A., Royo Plumed, H. y González Soutelo, S. 20I4: «Archaeometric Characterization and First Distribution Study of a Spanish Marble used in Antiquity: The Marble from O Incio». 40 ${ }^{\text {th }}$ International Symposium on Archaeometry (ISA2OI4), Program and Abstract Book. Los Angeles: 98-99 (póster).

Gutiérrez Garcia-M., A., Royo Plumed, H. y González Soutelo, S. (en prensa-a): «New data on Spanish marbles: the case of Gallaecia (NW Spain)», Proceedings of the XI ASMOSIA Conference (Split 20I5).

Gutiérrez Garcia-M., A., Royo Plumed, H., González Soutelo, S., Savin, M.-C., Lapuente, P. y Chapoulie, R. (en prensa -b): «The marble of O Incio (Galicia, Spain): quarries and first archaeometric characterisation of a material used since Roman times». Archéosciences, Revue d'archéometrie.

Hermann, J., Herz, N. y Newman, R. (eds.) 2002: ASMOSIA V, Interdisciplinary Studies on Ancient Stone. Proceedings of the Fifth International Conference of the Association for the Study of Marble and Other Stones in Antiquity. London.

Jockey, PH. (ed.) 2009: La Pierre dans tous ses états. ASMOSIA VIII. Proceedings of the $8^{\text {th }}$ International Conference of the Association for the Study of Marble and Other Stones used in Antiquity (Aix-en-Provence, France, I2-I8 June 2006). Maison méditerranéenne des sciences de l'homme. Paris.

Kollwitz, J. y Herdejürgen, H. I979: Die Ravennatischen Sarkophage, A.S.R. vol. VIIl-2. Berlin.

Lapuente, P. y Álvarez, A. 20I2: «Métodos para la identificación de los mármoles». En V. García-Entero (ed.): El marmor en Hispania: explotación, uso y difusión en época romana. Madrid: 73-90.

Lapuente, P., Turi, B. y Blanc, P. 2000: «Marbles from Roman Hispania: stable isotope and cathodoluminescence characterization». Applied Geochemistry I5 (I0): I469-I493.

Lapuente, P., Nogales-Basarrate, T., Royo, H. y Brilli, M. 20I4: «White marble sculptures from the National Museum of Roman Art (Mérida, Spain): sources of local and imported marbles». European Journal of Mineralogy 26: 333-354.

lapuente, P., Nogales-Basarrate, T., Royo, H., Brilli, M., Savin, M.C. (en prensa): «Grey and greyish banded marbles from the Estremoz Anticline in Lusitania», Proccedings of the XI ASMOSIA Conference (Split 20I5).

López Lombo, L. 2003: O Incio. Paisaje, historia y patrimonio. Salamanca.

Lorenzo Fernández, J. 1953: «La capilla visigoda de Amiadoso». Archivo Español de Arqueología 26: 424-433.

LORENZO FernándeZ, X. I965: «La iglesia prerrománica de San Martiño de Pazó». Cuadernos de Estudios Gallegos 20, fasc. 61: 180-192.

MACIEL, J. I996: Antigüidade tardia e paleocristianismo em Portugal. Lisboa.

Maniatis, Y. (ed.) 2009: ASMOSIA VII. Proceedings of the $7^{\text {th }}$ International Conference of the Association for the Study of Marble and Other Stones used in Antiquity. Bulletin de Correspondance Hellénique. Athènes.

Mathea-Förtsch, M. I999: Römische Rankenpfeiler und Pilaster. Mainz am Rhein.

Mossch, V. 2000: «Pilastri con decorazione vegetale». Adriano architettura e progetto. Milano: 204-205, $\mathrm{n}^{\circ}$ cat. $20 \mathrm{a}$.

NAVARRO, R. 1988: «Necrópolis y formas de enterramiento de época cristiana en las Baleares. El mundo funerario». Les Illes Balears en temps cristians fins als àrabs. Ciutadella: 25-40. 
Nogales Basarrate, T. y Beltrán Fortes, J. 2009: Marmora hispana: explotación y uso de los materiales pétreos en la Hispania romana. Roma.

NúÑEz Rodríguez, M. I976: «Aproximación al estudio de las formas ornamentales en Galicia durante la época visigoda». Revista de Guimarâes 86: 177-186.

NúÑEz Rodríguez, M. I978: Historia da arquitectura galega. Arquitectura prerrománica. Madrid.

Osaba y Ruiz de Erenchun, B. I946: «Relieve visigótico inédito y dos cruces mozárabes también inéditas». Boletín del Museo Arqueológico de Ourense 2: 5-23.

Osuna, O. 1976: Museo de Cuenca. Secciones de Arqueología y Bellas Artes. Col. Museos de España, serie Guías 6o. Madrid.

PALOL, P. de 1967: Arqueología Cristiana de la España Romana. Siglos IV-VI. Madrid-Valladolid.

Pensabene, P. y Gasparini, E. (a cura di) 2015: ASMOSIA X, Proceedings of the Tenth International Conference, Interdisciplinary Studies on Ancient Stone. Roma.

Pessoa, M. y Steinert, S. 20or: «Villa romana do Rabaçal, Penela, Portugal -Contributo para o estudo dos baixo-relevos e outros elementos de escultura arquitectónica». Actas do $3^{\circ}$ Congresso de Arqueologia Peninsular (Vila Real, 1999), vol. Vl. Braga: 709-740.

Puga BraU, J. 1946: «¿Cuándo y dónde nació el Cicerón Gallego, Tertuliano español y Fénix de la elocuencia?». Boletín del Museo Arqueológico Provincial de Ourense 2: 45-55.

RIVAS FERNÁNDEZ, J.C. I976: «Un inédito e interesante vestigio de la iconografía visigótica en Galicia, procedente de la iglesia prerrománica de San Martiño de Pazó». Boletín Auriense 6: 169-182.

Rodríguez Colmenero, A. I993: «Escultura en relieve y bulto redondo». Galicia. Arte, IX. A Coruña: 372-475.

SÁNCHEZ PARDO, J.C. 20Iza: «Los contextos de fundación de las iglesias tardoantiguas en Galicia (ss. V-VIII): substratos arqueológicos, distribución y significados». Antiquité Tardive 20: 255-273.

SÁNCHeZ PARDO, J.C. 2OIzb: «Arqueología de las iglesias tardoantiguas en Galicia (ss. V-VIll). Una valoración de conjunto». Hortus Artium Medievalium I8-2: 395-4I3.

SÁNCHEZ PARDO, J.C. 20I5: «El reuso de materiales y estructuras antiguas en las iglesias altomedievales de Galicia. Casos, problemas y motivaciones». Estudos do Quaternário I2, APEQ: 95-IIO.

SAPElli, M. I998: Museo Nazionale Romano. Arte tardoantica in Palazzo Massimo alle Terme. Roma.

SAPELli, M. 200I: «Cràtera amb grues i serps», Tarraco porta de Roma. Barcelona: I28, $\mathrm{n}^{\circ}$ cat. I05.

Schlunk, H. 1947: Arte visigodo. Arte asturiano, Ars-Hispania II. Madrid.

SChVoerer, M. (ed.) I999: Archéomateriaux. Marbres et autres roches. Actes de la IVe Conference internationale ASMOSIA IV. Bordeaux.

Severin, H. G., I970: «Oströmische Plastikunter Valens und Theodosius I». Jahrbuch der Berliner Museen I2: 2II-252.

SingUL, F. I999: «La pintura de Santa Eulalia de Bóveda (Lugo). Significado y relaciones con el arte paleocristiano y la pintura asturiana». Boletín Auriense 28: 59-84.

Toynbee, J. M. C. y Ward Perkins, J.B. I950: «Peopled Scrolls: A Hellenistic Motif in Imperial Art».Papers of the British School at Rome XVIII (New Series vol. V): I-43, láms. I-XXVI.

Utrero Agudo, $M^{a}$.A. y Sastre de Diego, I. 20I3: «Reutilizando materiales en las construcciones de los siglos VII-X. ¿Una posibilidad o una necesidad?». Anales de Historia del Arte 22: 309-323. 
VALLE PÉREZ, X.C. 1984: «Escultura paleocristiana y prerrománica». Gran Enciclopedia Gallega X. Santiago de Compostela: I32-I35.

VAlLe Pérez, X.C. 20I2: «De la Gallaecia antigua a la Gallaecia moderna: la piedra como marco, como soporte y como ornato durante la Edad Media (siglos IV al XVI)». Gallaecia Petrea. Santiago de Compostela: 330-339.

Varela, T. A., Pérez losada, E. y Rodríguez Colmenero, A. 2007: «Los hallazgos paleocristianos de Licín, O Saviñao, Lugo». Larouco: Revista anual da antigüedade galaica 4: 230-23I.

VARGAS Costa, M.L. I985: «Contribução para o estudo de alguns mosaicos da Villa romana de «Pições»». Arquivo de Beja, 2 ${ }^{\mathrm{a}}$ série, II: 95-I35.

Vézquez Castro, J. 2005: «Arquitectura en Galicia durante la Alta Edad Media». Arte y Cultura de Galicia y Norte de Portugal. Arquitectura. Vigo: 47-66.

Veiga Romero, A.M. 2005: «Relevo decorativo». Museo Arqueolóxico de Ourense Peza do Mes 03/2005. Ourense.

VIDAL Álvarez, S. 2005: La escultura hispánica figurada de la Antigüedad Tardía (siglos IVVII). Murcia.

VIDAL ÁlLVAREZ, S., 2007: «Nuevos datos para el estudio de la producción de sarcófagos del noroeste de la Península Ibérica entre los siglos IV-VI: el sarcófago de Portosín (A Coruña) y los relieves de Gijón (Asturias)». Akten Symposium des Sarkophag-Corpus $200 I$. Mainz am Rhein: 215-23I.

Vidal Álvarez, S. y García-Entero, V., 20I5: «The use of Estremoz Marble in Late Antique Sculpture of Hispania: New data from the Petrographic and cathodoluminiscence analyses». En P. Pensabene y E. Gasparini (a cura di): Interdisciplinary Studies on Ancient Stone ASMOSIA X. Proceedings of the Tenth International Conference of ASMOSIA (Association for the Study of Marble \& Other Stones in Antiquity). Roma: 4I3-42O.

Vidal Álvarez, S., García-Entero, V. y Gutiérrez Garcia-M., A. 2016 (en prensa): «La utilización del mármol de Estremoz (Portugal) en la escultura tardorromana: los sarcófagos». XI Congreso Peninsular de Arqueometría (Évora 2015).

YzQuierdo Perrín, R. I993: Arte Medieval (I), Galicia. Arte X. A Coruña: II3-I55. 


\section{Artículos}

\section{Alfredo Cortell Nicolau}

Ocre, hematites y óxido de hierro: el problema terminológico

Ochre, Hematite and Iron Oxid: The Terminological Issueu

43 Hipólito Pecci Tenrero

El Empleo de Armamento como elemento de aporte cronológico al arte rupestre Postpaleolítico del Cerro de San Isidro (Domingo García, Segovia) The Use of Weapons as an Element of Chronological Contribution to the Post-Paleolithic Rock Art at the Cerro de San Isidro (Domingo García, Segovia)

\section{SARA ARROYO CUADRA}

Los narû (kudurrētu) babilónicos del Bronce Final y el Hierro

The Babylonian narû (kudurrétu) in Late Bronze and Iron Age

Silvia G.onzález Soutelo \& Sergio Vidal Álvarez \& Anna Gutiérrez Garcia-M. \& Hernando Royo Plumed

La placa de Amiadoso (Allariz, Ourense): Nuevos datos sobre el uso del mármol local en el noroeste de Hispania

The Amiadoso plaque (Allariz, Ourense): New Data from an Interdisciplinary Study about the Use of Local Marble in the NW of Hispania

\section{Ana Bejarano Osorio}

Contribución al estudio de los espacios termales de Augusta Emerita: el Balneum De La C/ Hernán Cortes y los modelos de doble alvei Contribution to the Thermal Spaces of Augusta Emerita: the Balneum of C/ Hernán Cortés and the Double Models of alvei.

\section{Luis Manuel Sánchez González}

Arroyo del Pedroso II: un asentamiento visigodo en La Jara Cacereña Arroyo del Pedroso II: A Visigoth Settlement in the Jara Cacereña 